\title{
A Research on How Work Experience Influencing Mental Quality of Entrepreneurs
}

\author{
Zhang Li Li \\ School of Business Administration, University of Science and Technology Liaoning \\ PO box 114051, 185 Qianshan Zhong Road, Anshan, Liaoning, China \\ Tel: +86-188-4127-4352Ｅ-mail: zhangliqinzhi@126.com
}

Received: June 18, 2011 Accepted: August 1, $2011 \quad$ doi:10.5430/ijba.v2n3p113

High School Education Research Business Program of 2009, NOJG10DB133; New Period of Liaoning Province of Economic Management Professional College Students Employment Education Pattern and Practice System Startup NO2009, 141.

\begin{abstract}
In order to explore and test how experience effecting mental quality, this paper constructs the evaluation index system of work experience in the perspective of post experience and organizational experience, and this paper constructs the evaluation index system of mental quality in the perspective of personality factor, decision factor and health factor. Based on this, testing the relationship between experience and mental quality according to the data of questionnaire investigation is researched. The results demonstrate that organization experience has positive effects on personality factors, decision factors and health factors, job experience does not has effects on mental quality. At last, based on the problems-finding, it gives some thinking.
\end{abstract}

Keywords: Entrepreneurs, Experience, Mental quality

\section{Introduction}

The openness of psychological quality system determines its inevitability with the interaction external and internal environment. Therefore, with considerable time of learning and working experiences, the psychological quality will gradually develop and mature with a stable trajectory path in dependent with the psychological condition. As individual psychological quality is key elements of enterprise success, psychological quality and work experience are very important from the perspective of both and target post match degrees and work experience to the psychological quality of the action mechanism, it is the practice of urgent need to address the problem. However, practical demands are not matching to the theory in the systematical research of psychological quality of entrepreneurs. Relevant working experience deals with little impact on the study of psychological quality. Based on this, the paper takes entrepreneurs group as the research object, and tries to dig for psychological quality is in the deep influence on the working experience, the different types of clarity to the psychological quality of the function mechanism of different dimensions, so as to improve the psychological quality to help entrepreneurs.

\section{Literature Review}

Along with the development of psychology, people gradually realize the question that psychological quality of work experience is very important (Adya, 2008), (Leunga, etal.,2008), (Cole, Elliott, Robert, Strobl, Eric.,2008). Work experience of managers affects decision information procedural decision and choice preference of thinking mode, helps straighten procedural problems solution (Goldman, 2008), (Foguem, Coudert, Béler, Geneste, 2008), (Patzelt, Holger, Knyphausen-Aufse, Dodo, Nikol, Petra.,2008). High density work experience will enhance personal in the rapidly changing environment in the face of the work motivation, working trouble (Pulakos, Arad, Donovan, Plamondon, 2000), (Lin, 2008); experienced managers are easier to establish the upheaval in the confidence to overcome all difficulties (Ko, Dennis,2011). In addition, through the working experience, the overall cognitive ability, motivation and job-related skills are able to obtain considerable growth. Individual experience, the organization situation to accomplish the task challenging is complex, the leadership and training which makes get the chance of post exercise, the organization performance evaluation and feedback system etc will affect the personal psychological quality (Zoogah,2010), (Huckman, Staats, and David, 2009). To sum up, from existing psychological quality development research, it can be seen that theoretical studies are more, empirical researches are less. And in empirical studies, resulting in the psychological quality often stays in the theoretical exploration level of psychological quality development; it is difficult 
to make substantial guidance. In view of this, this paper explores entrepreneurs as the scene of its working experience in variables to the influence of the psychological quality, so as to provide the psychological diathesis development entrepreneurs for reference.

\section{Working Experience of Entrepreneurs Influence Psychological Quality on the Proposed Assumptions}

Assumption 1a: Entrepreneurs' grassroots position working experience has positive effects on the personality factors; Assumption 1b: Entrepreneurs' grass-roots position working experience has positive impact on decision factors; Assumption 1c: Entrepreneurs' grass-roots position working experience has positive impact on psychological health factors. Assumption 2a: Entrepreneurs’ organizational experience has positive impact on personality factors. Assumption 2b: Entrepreneurs' organizational experience has positive impact on decision factors. Assumption 2c: Entrepreneurs' organizational experience has positive impact on health factors.

\section{The Research Process}

\subsection{Data Sources and Description}

Data comes from the psychological quality and work experience of entrepreneur's questionnaire. The questionnaire is made by Richter magnitude scale, the questionnaire is used for asking respondents to answer each of the question by which measurement is most like, among this"1 " means " significant deficiencies "; "2" means "insufficient as well"; "3" means "general"; "4" means "good"; "5" means "rich". The questionnaire is designed with the help of MBA students by local working relationship and interpersonal relationship to launch an investigation, and supplemented by mail, telephone and so on, it is investigated in many kinds of ways. The process is through three months (2010 July - 2010 October), for a total of 700 copies of questionnaires, sorting out the invalid questionnaires, there were 527 valid questionnaires with a usability rate of $75.3 \%$. Among them, the answerers distribute among the following 14 provinces: Beijing, Gansu, Guangdong, Guangxi, Hebei, Hubei, Jiangsu, Liaoning, Qinghai, Shandong, Sichuan, Yunnan, Zhejiang, Chongqing. Age distribution: 30 to 40 years old 31 people, 41 years old to 50 years old, 51 years old 301188 people otherwise seven people, therefore the not. Degree: college and below 16 people, undergraduate 148 people, graduate students, Ph.D. 44 306, others 13.

\subsection{Work Experience and Psychological Quality Scale Reliability and Validity Analysis}

By applying the SPSS16.0 software, the reliability analysis of Cronbach coefficient is calculated. The result is that 0.604 for the gamerelease, work experience scale has good reliability level. In validity inspection, work experience in the significant level was 0.000 freedom for 15 , chi-square value is 201.092, sample measure that 0.614 , value between variables can significantly related, causal analysis. Using principal component analysis, extraction characteristic value of common factor, greater than 1 with maximum variation coefficient method for the orthogonal rotating, after maximum orthogonal rotating, withdraw two factors, the result is shown in table 1. In variables together degrees aspects, all value exceeds 0.5 , shows that scale had good structural validity. When two factors, the extracted eigenvalues are greater than 1 , accumulative total variance explained $61.614 \%$ (standard for rate of greater than or equal to $60 \%$ ).

\subsection{Psychological Quality Scale Reliability and Validity Analysis}

By applying SPSS16.0 software, the reliability analysis of Cronbach 's calculated coefficient for the gamerelease is 0.909, psychological quality scale has good reliability level. In validity inspection, KMO and Bartlett is good for the factor analysis of the feasibility investigation, psychological quality scale in the significant level, 0.000 freedom for 55 , chi-square value is $1.331 \mathrm{E} 3$, sample measure is 0.901 .It was significantly related based on principal component analysis, extraction characteristic value of common factor, greater than 1 with maximum variation coefficient method for the orthogonal rotating, after maximum orthogonal rotating, in extracting the premise of three factors, get the load various factors, as shown in chart 2. In a variable, and the minimum common degrees aspects for 0.587, explains most of the mutation. Observed variables indicate that scale had good structural validity. This questionnaire extraction, the three factors are greater than 1 characteristic value, the cumulative variance explained $71.045 \%$ (standard for rate of greater than or equal to $60 \%)$.

\subsection{Psychological Quality and Working Experience of Entrepreneurs Affecting Path Analysis}

This paper uses LISREL8.3 software, through the maximum likelihood estimation to get the final regression results. The results show that the selected $\chi 2 / d f, N F I, R F I, I F I, C F I, R M S E A$ fitting effect testing model standards are within the acceptable limits, it demonstrates the fitting degree of the ideal model and observation data is good. Some scholars think the qualify value is between 0.08 and 0.1 , according to this standard, this model may be accepted, slightly above 0.08 , it is 0.082 , the model and data fitting effect can be accepted, the fitting result is shown in table 3.

Among them, the model is all the work experience model are as independent variables and dimension of psychological 
quality as the dependent variable regression, the result shows that organization experience on personality factors, decision factors, heart health factors in the path coefficient, under the significant level respectively to strike, height, reached 0.90 . Work experience for the influence of three psychological quality are not significant. Specific results are shown in figure 2.

\subsection{Hypothesis Test Results Discussed}

It can be seen from figure 2, there is no significant influence about work experience on personality factors, emotional factors, decision factors, and the assumption 1 is not verified. This phenomenon may exist for the following reasons: from the survey of samples, age distribution feature for 30 to 40 years old is 31 people, 41 years old to 50 years old, 51 years old 301188 people over 40. To a great extent, most of these workers engaged in work in a totally planned economy, competition is relatively small, independent decision-making opportunity is not much, changes in the environment is relatively small, the psychological quality of management efficiency, so there is no significant difference of the work experience based on post psychological quality, the effect is not reflected. Organization experience on personality factors, emotional factors, decision factors was significantly influence, the assuming 2 is verified.

\section{Conclusion and Enlightenment}

The psychological quality is constructed from personality factors; decision factors, mental health factors, and empirical analysis index system of the relationship between them are researched. Research shows that the entrepreneurs of personality factors, organizational experience decision factors, mental health factors have significant positive effects, and the results can provide a new perspective for psychological quality development strategy. However, work experience does not influence psychological quality dimensions significantly, for this phenomenon; this paper gives the corresponding explanation.

\section{References}

Adya, Monica P. (2008)Women at Work: Differences in IT Career Experiences and Perceptions between South Asian and American Women[J].Human Resource Management,47(3).601-635. doi.1002/hrm.20234.http://onlinelibrary.wiley.com/doi/10.1002/hrm.20234

Angela Ka-yee Leunga, etal. (2008)Multicultural Experience Enhances Creativity: The When and How[J].American Psychologist,63(3). 169-181.doi=10.1037/0003-066X.63.3.169.http://psycnet.apa.org/journals/amp/63/3/169/

Cole, Matthew A,Elliott,Robert J.R. Strobl,Eric.(2008)The Environmental Performance of Firms: The Role of Foreign Ownership, Training, and Experience[J].Ecological Economics,65(3). 538-546.doi:10.1016/j.ecolecon.2007.07.025.http://www.sciencedirect.com/science/article

David B. Zoogah.(2010)Cross-cultural experience, strategic motivation and employer hiring preference: An exploratory study in an emerging economy[J].International Journal of Cross Cultural Management,2010,10 (3).321-343. doi:10.1177/1470595810384584.http://ccm.sagepub.com/content/10/3/321.short

Dong-Gil Ko, Alan R. Dennis.(2011)Profiting from Knowledge Management: The Impact of Time and Experience[J]. INFORMATION SYSTEMS $\quad$ RESEARCH,22(1). $134-152$. doi:10.1287/isre.1090.0247.http://portal.acm.org/citation.cfm?id=1964158

Goldman, Ellen F.(2008)The Power of Work Experiences: Characteristics Critical to Developing Expertise in Strategic Thinking[J].Human Resource Development Quarterly,19(3).217-239. doi:10.1002/hrdq.1237.http://onlinelibrary.wiley.com/doi/10.1002/hrdq.1237/

Kamsu Foguem, Coudert, T, Béler, C. Geneste, L.(2008)Knowledge Formalization in Experience Feedback Processes: An Ontology-based Approach[J].Computers in 694-710.doi:10.1016/j.compind.2007.12.014.http://www.sciencedirect.com/science/article

Patzelt,Holger, Zu Knyphausen-Aufse, Dodo, Nikol, Petra.(2008)Top Management Teams, Business Models, and Performance of Biotechnology Ventures: An Upper Echelon Perspective [J].British Journal of Management,19(3).205-221.doi:10.1111/j.1467-8551.2007.00552.x.http://onlinelibrary.wiley.com/doi/10.1111/j.14 67-8551.2007.00552.x/full

Pulakos E.D, Arad S, Donovan M.A, Plamondon K.E. (2000)Adaptability in the Workplace: Development of a Taxonomy of Adaptive Performance[J]. Journal of Applied Psychology,85(4). 612-624.doi:10.1037/0021-9010.85.4.612.http://nreilly.asp.radford.edu/pulakos\%20arad\%20donovan\%20plamond on.pdf 
Robert S. Huckman, Bradley R. Staats, and David M.(2009)Upton.Team Familiarity, Role Experience, and Performance: Evidence from Indian Software Services[J].Management Science, (55).85-100. doi:10.1287/mnsc.1080.0921.http://portal.acm.org/citation.cfm?id=1535865

Yu-Cheng Lin.(2008)Developing Construction Assistant Experience Management System Using People-based maps[J].Automation in Construction, $\quad$ 17(8). doi:10.1016/j.autcon.2008.04.004.http://www.sciencedirect.com/science/article/pii/S0926580508000630

Table 1. Working experience exploratory factor analysis

\begin{tabular}{|l|c|c|}
\hline & factor 1 & factor 2 \\
\hline Basic work experience & .875 & .029 \\
\hline Incumbent post similar working experience & .658 & .083 \\
\hline A variety of work position working experience & .841 & .013 \\
\hline Large enterprise unit work experience & -.118 & .694 \\
\hline Large institution work experience & .174 & .828 \\
\hline Study abroad and work experience & .104 & .749 \\
\hline
\end{tabular}

Table 2. After turn factor loading matrix

\begin{tabular}{|c|c|c|c|}
\hline & factor 1 & factor 2 & factor 3 \\
\hline Mentality clear & .773 & .225 & .257 \\
\hline Agile thinking & .641 & .577 & -.017 \\
\hline broad-minded & .623 & .152 & .596 \\
\hline tough-minded & .663 & .294 & .246 \\
\hline Right from wrong & .687 & .151 & .507 \\
\hline Positive enterprising & .771 & .286 & .045 \\
\hline insight & .334 & .724 & .257 \\
\hline Intuition and foresee & .414 & .636 & .176 \\
\hline Modest and prudent & .358 & .188 & .757 \\
\hline flexible & .120 & .797 & .338 \\
\hline Mood stability & .013 & .324 & .812 \\
\hline
\end{tabular}

Table 3. Model fitting index output

\begin{tabular}{|c|c|c|c|c|c|c|}
\hline Model type & $\chi 2 / d f$ & NFI & RFI & $I F I$ & CFI & RMSEA \\
\hline Default mode & 5.944 & 0.809 & 0.741 & 0.836 & 0.834 & 0.082 \\
\hline Saturated mode & - & 1.000 & - & 1.000 & 1.000 & - \\
\hline Independent mode & 22.978 & 0.000 & 0.000 & 0.000 & 0.000 & 0.206 \\
\hline
\end{tabular}




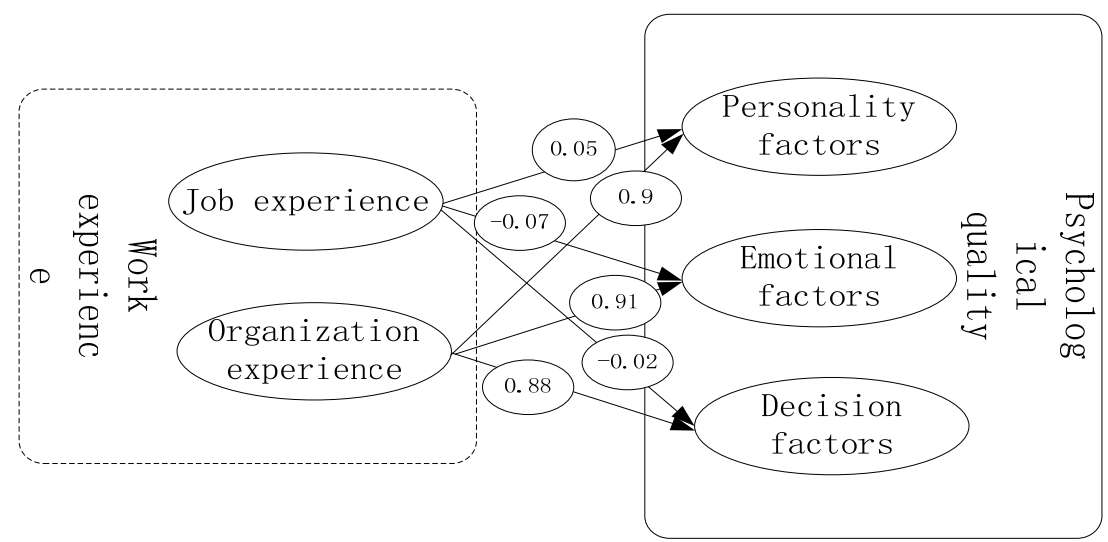

Figure 1 . The relationship between work experience and psychology quality 